\title{
Pharyngeal Residue
}

National Cancer Institute

\section{Source}

National Cancer Institute. Pharyngeal Residue. NCI Thesaurus. Code C106103.

Substance remaining in the pharynx after swallowing. 